\title{
Viral-associated trichodysplasia in a patient with lymphoma: a case report and review
}

Viral-associated trichodysplasia is a recently described entity associated with immunosuppression. We describe a 68-year-old man with a history of treated lymphoma who developed numerous, disfiguring, papular and spiny lesions involving most of the central face. Both facial and body alopecia was noted. Histopathologic findings of a facial papule showed dramatic alterations of the hair bulbs, including bulbar distention, lack of hair shaft formation and a marked expansion of inner root sheath type epithelium. These findings were identical to those of previously described cases, so electron microscopy was performed. Numerous intranuclear virus particles were identified. Shortly after the diagnosis of trichodysplasia was made, the patient was found to have a relapse of his lymphoma, which may represent the source of his immunosuppression. Based on his skin biopsy findings, successful antiviral therapy was initiated. This case and a review of previously reported cases are discussed in this study.

Osswald SS, Kulick KB, Tomaszewski M-M, Sperling LC. Viralassociated trichodysplasia in a patient with lymphoma: a case report and review.

J Cutan Pathol 2007; 34: 721-725. (C) Blackwell Munksgaard 2006.
Sandra S. Osswald ${ }^{1}$, Kevin B. Kulick ${ }^{2}$, Maria-Magdalena Tomaszewski ${ }^{3}$ and Leonard C. Sperling ${ }^{4}$

${ }^{1}$ Department of Dermatology, Brooke Army Medical Center, Fort Sam Houston, TX, ${ }^{2}$ Department of Dermatology, School of Medicine and Biomedical Sciences, State University of New York, Buffalo, NY

${ }^{3}$ Department of Dermatopathology, Armed Forces Institute of Pathology, Washington, $\mathrm{DC}$, and

${ }^{4}$ Department of Dermatology, Uniformed Services University of the Health Sciences, Bethesda, MD, USA

Sandra S. Osswald, USAF, Department of Dermatology, Brooke Army Medical Center, Fort Sam Houston, TX 78234, USA

Tel: +1 210-916-5653

Fax: +1 210-916-3103

e-mail: ssosswald@aol.com

Accepted for publication October 22, 2006
There has been increasing recognition of a distinctive facial dermatosis comprising follicular papules and spines with progressive alopecia, associated with peculiar histologic alterations of the hair follicles. This clinicopathologic pattern was initially described in patients who had undergone organ transplantation and were on immunosuppressive therapy with cyclosporine. Subsequently, it was seen in patients who had undergone organ transplantation and were on immunosuppressive drugs other than cyclosporine. More recently, there was the first report of a patient who had not undergone organ transplantation but may have been immunocompromised from acute lymphocytic leukemia. The condition has been variously named 'pilomatrix dysplasia', 'cyclosporineinduced folliculodystrophy', ${ }^{2}$ 'virus-associated trichodysplasia spinulosa' 3 and 'viral-associated trichodysplasia (VAT) of immunosuppression ${ }^{4}$ but appears to represent one entity associated with a folliculotropic viral infection.

\section{Case report}

A 68-year-old man had been diagnosed in 1993 with non-Hodgkin's lymphoma, low-grade follicular type. The lymphoma went into remission with chemotherapy but recurred twice during the ensuing years. His most recent recurrence was in 2003, and he was successfully treated with fludarabine and rituximab. A follow-up gallium scan in 2005 was negative for lymphoma. He presented to the dermatology department in November 2005 with a 1-year history of progressive facial thickening and follicular prominence with accompanying loss of hair. He had had a history of androgenetic alopecia for many years. However, he developed thickening of his skin, particularly his central face with involvement of his eyebrows, glabella, nose, chin and ears (Fig. 1). He had multiple dilated follicular ostia and flesh-colored follicular papules, some with spinous protuberances with progressive alopecia of these areas (Fig. 2). The initial clinical impression included leonine facies, 


\section{Osswald et al.}

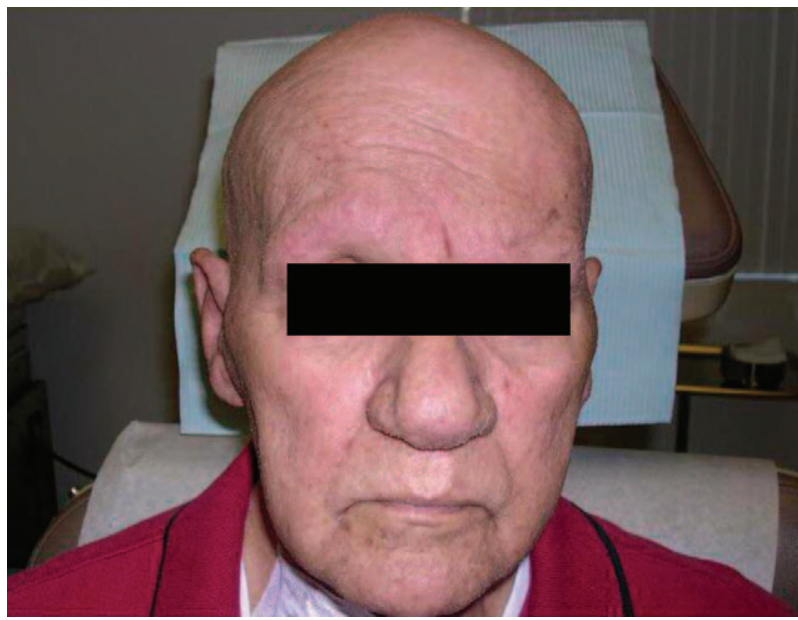

Fig. 1. Thickening of the eyebrows, glabella and nose.

perhaps because of lymphoma. The lesions were asymptomatic and he felt otherwise well.

Three months after first visiting the dermatology department, he experienced increasing fatigue and weakness and was diagnosed with recurrent lymphoma and generalized herpes zoster. $\mathrm{He}$ was treated with fludarabine, rituximab and intravenous acyclovir. Although his general health improved after receiving chemotherapy, his skin lesions spread from his face to his shoulders, posterior arms, upper abdomen and legs. Sparse hair was found on his mid-chest, axillae and pubic regions. His cutaneous differential diagnosis was expanded to include alopecia mucinosa, scleromyxedema and drug reaction.

Histopathologic evaluation showed bulbous and massively distended hair follicles. The upper segment of the follicle showed a dilated, hyperkeratotic and shaftless infundibulum. The bulb lacked an apparent hair papilla (Fig. 3). A thin rim of germinative cells surrounded a proliferation of inner root sheath type cells containing abnormally large trichohyaline granules (Figs. 4 and 5). These cells abruptly cornified without the presence of a granular

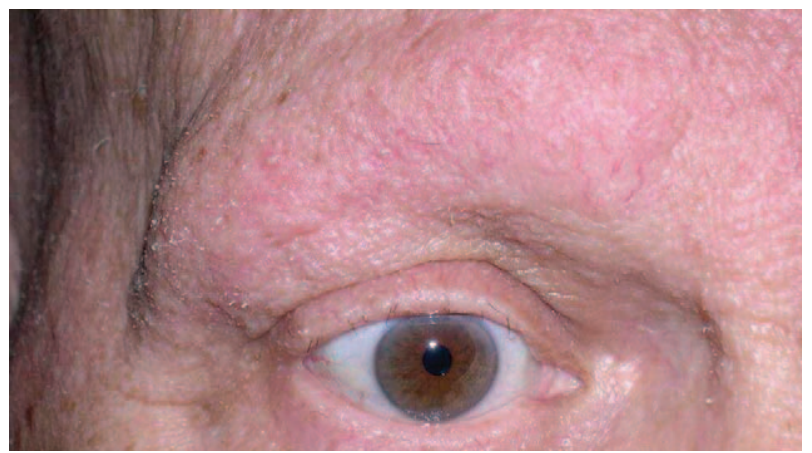

Fig. 2. Follicular papules and small, white spines with eyebrow and eyelash alopecia.

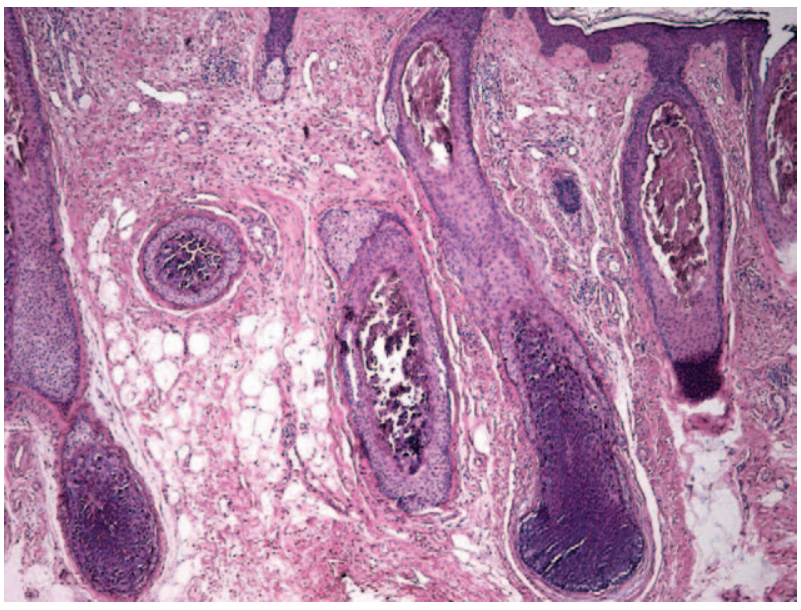

Fig. 3. Several bulbous and dilated hair follicles with keratotic plugging of the infundibulum. Follicles do not have identifiable hair papillae and are shaftless (hematoxylin-eosin stain, original magnification $\times 40)$.

cell layer. Nucleated cells with trichohyaline granules persisted throughout the lower segment of the follicle and occupied most of the follicular epithelium, with a relatively thin outer root sheath (Fig. 6).

Electron microscopic examination of inner root sheath type cells showed numerous intranuclear virus particles measuring approximately $40-45 \mathrm{~nm}$ in diameter (Fig. 7).

The constellation of findings was diagnostic of VAT of immunosuppression. Based on the diagnosis, the patient was started on cidofovir $1 \%$ in Vanicream $^{\mathrm{TM}}$ twice a day (cidofovir 3\% cream was not used because of the cost). The patient had noticeable improvement with diminution of follicular spines, regrowth of his beard hair and steady normalization of cutaneous findings in the following months.

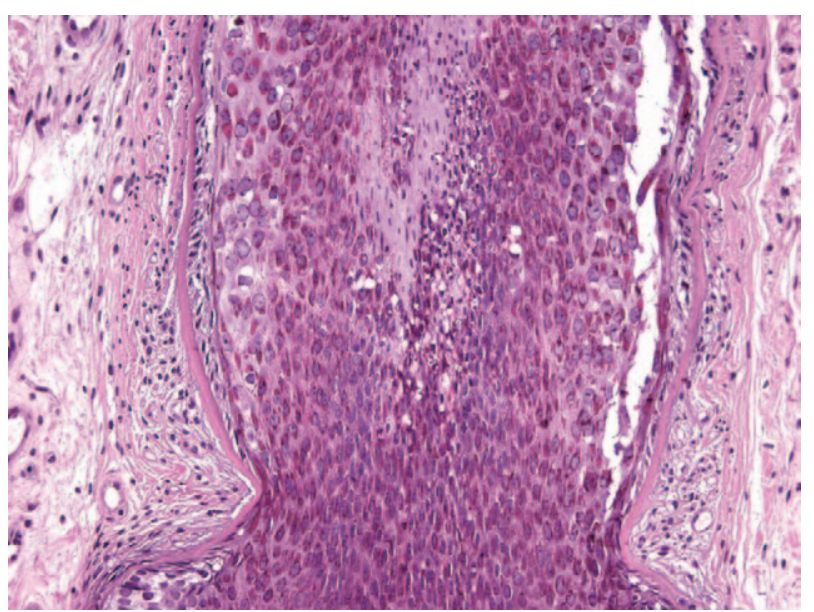

Fig. 4. Hair follicle with proliferation of inner root sheath type cells with abnormally large trichohyaline granules (hematoxylin-eosin stain, original magnification $\times 200$ ). 


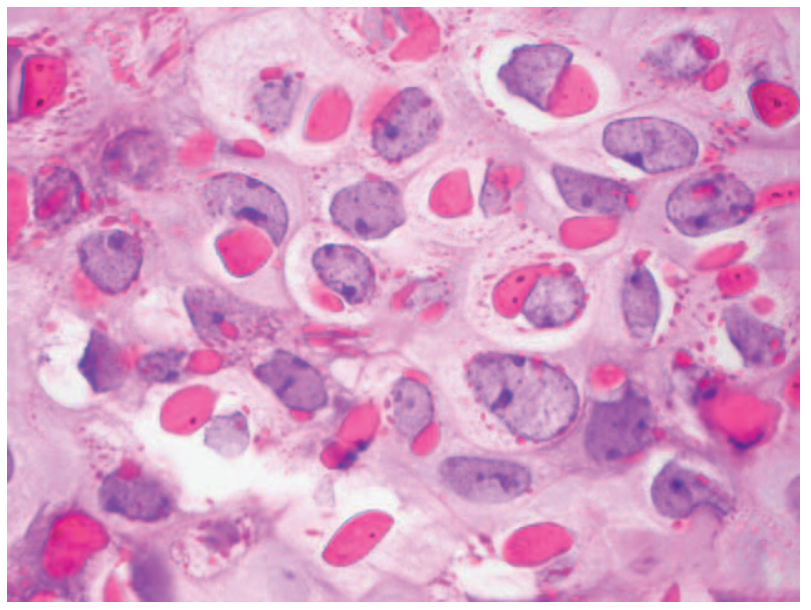

Fig. 5. Higher magnification of abnormally large trichohyaline granules (hematoxylin-eosin stain, original magnification $\times 1000$ ).

\section{Discussion}

The finding of VAT in a patient with lymphoma broadens the spectrum of associated diseases in patients who share a very distinctive follicular-based clinicopathologic entity. We believe that the unifying feature is relative immunosuppression rather than a specific associated disease or immunosuppressive medication.

In 1995, Izakovic et al. ${ }^{5}$ described hair-like facial hyperkeratosis in a 31-year-old patient with a renal transplant and postulated the cause as a reaction to cyclosporine. Chastain and Millikan ${ }^{1}$ in 2000 described a case of a 13-year-old girl with severe cystic fibrosis who had undergone bilateral lung transplantation, and again, cyclosporine was suspected as the causative agent. Heaphy et al. ${ }^{2}$ in 2004 likewise attributed their similar clinical and histopathologic findings to cyclosporine in a patient

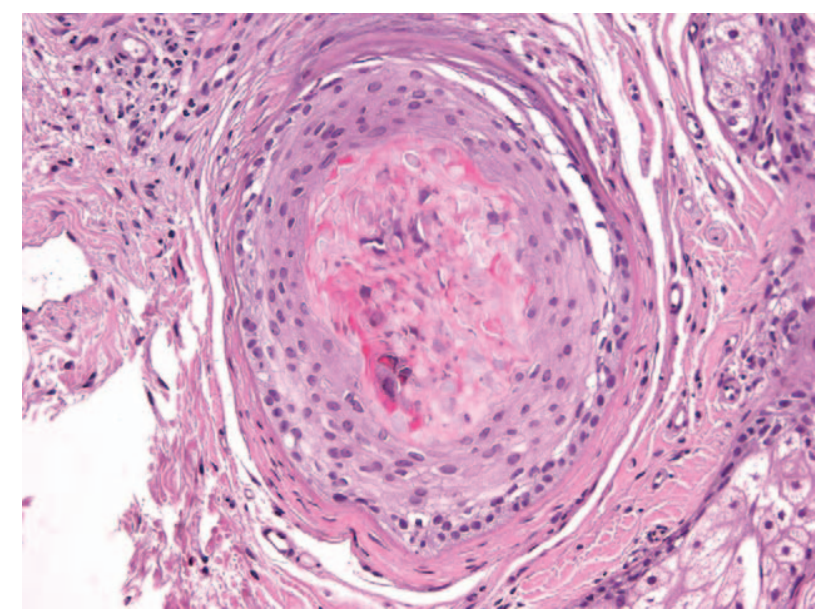

Fig. 6. Transverse section of the lower segment of hair follicle with nucleated cells with large trichohyaline granules and inner root sheath keratinization (hematoxylin-eosin stain, original magnification $\times 200$ ).

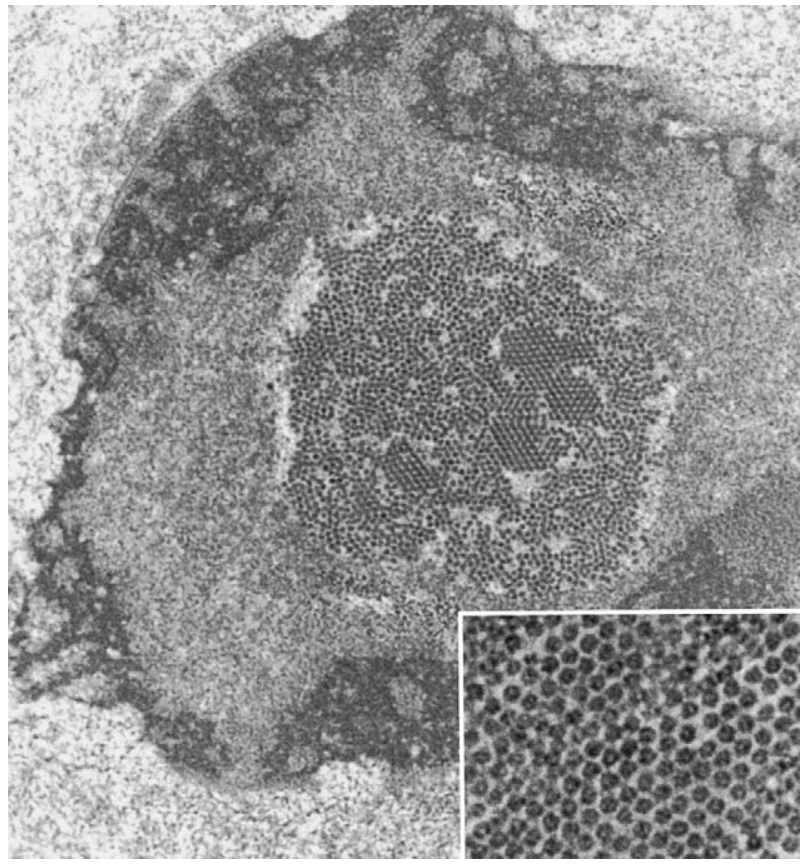

Fig. 7. Transmission electron micrograph showing clusters of intranuclear viral particles within the inner root sheath type cells (Original magnification $\times 20,000$, inset $\times 50,000$ ).

underwent renal transplantation. They found that lowering or discontinuation of the drug led to gradual improvement of the patient's findings in theirs and in the aforementioned previously reported cases.

In 1999, Haycox et al. ${ }^{6}$ described a remarkably similar condition they called 'trichodysplasia spinulosa' and found it to be associated with viral particles measuring $38 \mathrm{~nm}$ in diameter. Their patient was a 44-year-old man who had undergone a renal/ pancreas transplantation for diabetes mellitus and received an immunosuppressive regimen consisting of tacrolimus, azathioprine and prednisone. This patient had not been on cyclosporine.

Sperling et al. in 2004 reported an additional case in a patient underwent renal transplantation. ${ }^{4}$ This 13-year-old girl was on prednisone, tacrolimus and mycophenolate mofetil but not on cyclosporine. Histopathology was identical to that described by Haycox et al., ${ }^{6}$ and electron microscopy also showed viral particles of similar size. They called this entity 'VAT'.

Most recently, Wyatt et al. in 2005 described two more patients with VAT. ${ }^{3}$ One patient was an 8-yearold boy who developed similar clinical findings after a kidney transplantation for renal failure secondary to Henoch-Schonlein purpura. His immunosuppressive regimen included tacrolimus, mycophenolate mofetil and prednisone. The other patient was a 19-year-old man with a history of pre-B-cell acute lymphocytic leukemia. He had been treated with cyclophosphamide, vincristine, high-dose prednisone and intrathecal 
Osswald et al.

Table 1. Summary of clinical features

\begin{tabular}{|c|c|c|c|c|c|c|}
\hline Reference & $\begin{array}{l}\text { Age } \\
\text { (years) }\end{array}$ & Gender & $\begin{array}{l}\text { Distribution of } \\
\text { follicular papules }\end{array}$ & $\begin{array}{l}\text { Distribution of } \\
\text { alopecia }\end{array}$ & Medical history & $\begin{array}{l}\text { Immunosuppressant } \\
\text { medication history }\end{array}$ \\
\hline Izakovic et al. ${ }^{5}$ & 31 & M & Face and extremities & & Renal transplant & Cyclosporine and prednisone \\
\hline $\begin{array}{l}\text { Chastain and } \\
\text { Millikan }\end{array}$ & 13 & $\mathrm{~F}$ & $\begin{array}{l}\text { Face (nose, eyebrows), } \\
\text { ears, and proximal } \\
\text { extremities }\end{array}$ & $\begin{array}{l}\text { Eyebrows and } \\
\text { eyelashes }\end{array}$ & $\begin{array}{l}\text { Lung transplant } \\
\text { and cystic fibrosis }\end{array}$ & $\begin{array}{l}\text { Cyclosporine and } \\
\text { mycophenolate } \\
\text { mofetil, prednisone }\end{array}$ \\
\hline Heaphy et al. ${ }^{2}$ & 34 & $\mathrm{~F}$ & $\begin{array}{l}\text { Face (nose, eyebrows, } \\
\text { eyelashes, chin, upper } \\
\text { lip), ears and body }\end{array}$ & $\begin{array}{l}\text { Eyebrows, eyelashes } \\
\text { and body } \\
\text { (except scalp) }\end{array}$ & $\begin{array}{l}\text { Renal transplant } \\
\text { and systemic lupus }\end{array}$ & $\begin{array}{l}\text { Cyclosporine, mycophenolate } \\
\text { mofetil, prednisone } \\
\text { and tacrolimus }\end{array}$ \\
\hline Haycox et al. ${ }^{6}$ & 44 & M & $\begin{array}{l}\text { Face (nose, forehead), } \\
\text { ears and body }\end{array}$ & $\begin{array}{l}\text { Body (sparing some } \\
\text { scalp/pubic hair) }\end{array}$ & $\begin{array}{l}\text { Renal/pancreas } \\
\text { transplant } \\
\text { and type } 1 \text { diabetes }\end{array}$ & $\begin{array}{l}\text { Tacrolimus, azathioprine } \\
\text { and prednisone }\end{array}$ \\
\hline Sperling et al. ${ }^{4}$ & 13 & $\mathrm{~F}$ & Face (nose, malar, & $\begin{array}{l}\text { Eyebrows and } \\
\text { evelashes }\end{array}$ & Renal transplant & $\begin{array}{l}\text { Tacrolimus, mycophenolate } \\
\text { mofetil and prednisone }\end{array}$ \\
\hline Wyatt et al. ${ }^{3}$ & 8 & M & Face (nose), ears & & $\begin{array}{l}\text { Renal transplant, } \\
\text { Henoch-Schonlein } \\
\text { purpura }\end{array}$ & $\begin{array}{l}\text { Tacrolimus, mycophenolate } \\
\text { mofetil and prednisone }\end{array}$ \\
\hline Wyatt et al. ${ }^{3}$ & 19 & M & $\begin{array}{l}\text { Face, posterior } \\
\text { arms and thighs }\end{array}$ & Eyebrows & $\begin{array}{l}\text { Pre-B-cell acute } \\
\text { lymphocytic leukemia }\end{array}$ & $\begin{array}{l}\text { Cyclophosphamide, vincristine, } \\
\text { intrathecal methotrexate } \\
\text { and prednisone }\end{array}$ \\
\hline $\begin{array}{l}\text { Osswald et al. } \\
\text { (this study) }\end{array}$ & 68 & $M$ & $\begin{array}{l}\text { Face (nose, glabella, } \\
\text { eyebrows, chin), } \\
\text { ears and body }\end{array}$ & $\begin{array}{l}\text { Eyebrows, beard } \\
\text { hair and body }\end{array}$ & Non-Hodgkin's lymphoma & Fludarabine and rituximab \\
\hline
\end{tabular}

F, female; $M$, male.

methotrexate. He did not receive a bone marrow or stem cell transplant and was the first reported patient without a history of organ transplantation. His morphologic and histopathologic features were typical and electron microscopy confirmed the presence of viral particles in affected cells.

Our case adds lymphoma or its treatment as a source of relative immunosuppression and gives support to the hypothesis that it is immunosuppression, either from disease or from medication, which appears to predispose individuals to these peculiar viral-associated follicular findings.

Patients with VAT of immunosuppression develop an infiltrated appearance of the skin with multiple flesh-colored to erythematous follicular papules. Lesions have a predilection for the central face, particularly the eyebrows, glabella, nose, chin and ears. Follicular, friable, keratotic spine-like excrescences may replace hairs on the eyebrows, occasionally the eyelashes and other hair-bearing areas of the face. With time, surrounding areas of the face and involvement of the trunk and extremities may be seen. Scalp hair is typically less involved. The condition may be asymptomatic or mildly pruritic. The age range to date is between 8 and 69 years, with no known sexual predilection. A summary of these clinical cases is shown in Table 1 .

The histologic features suggest that the machinery of the hair bulb is converted from making hair shafts to making inner root sheath material. The 'spiny' projections seen clinically are not hair shafts but cornified inner root sheath cells. Inner root sheath type cornification can be identified by positive staining with toluidine blue.
The intranuclear, icosahedral viral particles identified by electron microscopy are morphologically suggestive of a polyomavirus. ${ }^{4,6}$ Viral cultures, human papillomavirus (HPV 6/11, 16, 18, 31/33/ $35 / 39,40 / 42 / 53 / 54,51 / 52 / 55 / 58$ and $45 / 56)$ and BK virus testing have been performed, by some investigators, but have been negative to date., ${ }^{3,6}$ Therefore, the causative agent has yet to be determined.

Topical steroids, topical tacrolimus, topical retinoids, topical antibiotics and minocycline have been used without success. ${ }^{2,3}$ The use of cidofovir $3 \%$ cream was shown to be useful in an anecdotal report. ${ }^{4}$ In our patient, cidofovir $1 \%$ in Vanicream ${ }^{\mathrm{TM}}$ was used topically twice a day with marked improvement after approximately 1 month of continuous treatment. No placebo-controlled trials have yet been conducted.

Our patient's presentation is remarkable for two reasons. First, the association of VAT with lymphoma has not been previously reported. Second, the emergence of VAT served as a harbinger of the relapse of the patient's lymphoma. The patient's immunosuppressed state, allowing for the emergence of VAT, may have been because of prior chemotherapy, factors secreted or induced by the lymphoma, general poor health because of the malignancy or a combination of these.

As predicted by Sperling et al., ${ }^{4}$ cases of VAT are becoming more widely recognized. All dermatologists and pathologists should be on the alert for the distinctive findings of this fascinating disease.

\section{Acknowledgements}

We would like to thank Dr Denis May for referring this case to the AFIP. 


\section{References}

1. Chastain M, Millikan L. Pilomatrix dysplasia in an immunosuppressed patient. J Am Acad Dermatol 2000; 43: 118.

2. Heaphy M, Shamma H, Hickmann M, White M. Cyclosporineinduced folliculodystrophy. J Am Acad Dermatol 2004; 50: 310 .

3. Wyatt A, Sachs D, Shia J, Delgado R, Busam K. Virus-associated trichodysplasia spinulosa. Am J Surg Pathol 2005; 29: 241.
4. Sperling L, Tomaszewski M, Thomas D. Viral-associated trichodysplasia in patients who are immunocompromised. J Am Acad Dermatol 2004; 50: 318.

5. Izakovic J, Büchner S, Düggelin M, Guggenheim R, Itin P. Spiny hyperkeratosis in a renal transplant recipient. A novel side effect of cyclosporine A. Hautarzt 1995; 46: 841.

6. Haycox C, Kin S, Fleckman P, et al. Trichodysplasia spinulosaa newly described folliculocentric viral infection in an immunocompromised host. J Investig Dermatol Symp Proc 1999; 4: 268. 